\title{
СОЦИАЛЬНО-ЭКОНОМИЧЕСКИЕ ДЕТЕРМИНАНТЫ ДЕТСКОЙ И ПОДРОСТКОВОЙ СМЕРТНОСТИ ОТ ВНЕШНИХ ПРИЧИН В МОСКВЕ
}

\author{
ЕКАТЕРИНА ВЕТРОВА
}

\begin{abstract}
Детская и подростковая смертность в России превышает показатели стран-лидеров по ожидаемой продолжительности жизни. Сущуественный вклад в это вносит смертность от внешних причин. Oпыт других стран показывает, что смертность от этого класса причин может быть значительно снижена при помощи мер сочиальной политики. В статье анализируется влияние сочииальных и экономических характеристик районов Москвы на смертность в них от внешних причин в детских и подростковых возрастных группах в 2016-2017 г. На основе данных Федеральной службы государственной статистики, ЦИАН, Базы данных показателей муниципальных образований, а также обезличенных данных ЗАГС Москвы были построены карты детской смертности Москвы и Тоbit-модели оценки коэффиџиента смертности в зависимости от сочиальных характеристик района. Выявлено, что для младшей возрастной группь от 1 до 4 лет наиболее значимым фактором является присмотр родителей, для более старших групп 5-9 лет значимыми становятся показатели дохода и благополучия района. Для подростковых возрастов 10-15 лет помимо дохода значимыми являются уровень преступности в районе и уровень экономического неравенства.
\end{abstract}

Ключевые слова: детская смертность, сочиальная политика, региональная политика, внешние причины смерти, избыточная смертность, Москва

\section{ВВЕДЕНИЕ}

Младенческая смертность (до возраста 1 год) регулярно выделяется в целях, касающихся развития здравоохранения (WHO 2014: 28; Assembly U.N.G. 2000 Assembly G. 2015). В связи с этим она находится под постоянным контролем и достаточно изучена исследователями. В то же время детской смертности от 1 года до 18 лет уделяется гораздо меньше внимания. Эта возрастная группа не была отмечена в Концепции долгосрочного социально-экономического развития Российской Федерации ${ }^{1}$ на период до 2020 г., сейчас не выделена в национальном проекте «Демография»². Тем не менее смертность в детских возрастах является индикатором как социальной обстановки, так и качества медицинских услуг (UNICEF 2016). Уровень детской смертности до 5 лет - один из индикаторов благополучия детей и социального развития страны (Shen, Williamson 1997). ЕКАТЕРИНА ДМИТРИЕВНА ВЕТРОВА (ekat.vetrova@gmal.com), МОСКОВСКИЙ ГОСУДАРСТВЕННЫЙ УНИВЕРСИТЕТ
ИМЕНИ М.В. ЛОМОНОСОВА, РОССИЯ.

СТАТЬЯ ПОСТУПИЛА В РЕДАКЦИЮ В ИЮЛЕ 2021 Г.

\footnotetext{
${ }^{1}$ Распоряжение Правительства РФ №1662-р от 17.11.2008 «Концепция долгосрочного социальноэкономического развития Российской Федерации на период до 2020 года». Ред. от 08.08.2009. СЗ РФ 2 Паспорт национального проекта "Демография" (утв. президиумом Совета при Президенте Российской Федерации по стратегическому развитию и национальным проектам, протокол №16 от 24.12.2018). URL: http://static.government.ru/media/files/Z4OMjDgCaeohKWaA0psu61Cekd3hwx2m.pdf
} 
В период с 2002 по 2010 г. в России был выявлен самый высокий уровень детской смертности по 30 европейским и североамериканским странам (Molcho et.al. 2015; Rajaratnam J.K. et.al 2010). В 2018 г. уровень смертности в детских возрастах в России попрежнему существенно превышал значения показателя в развитых европейских странах. Хотя коэффициент детской смертности по пятилетним возрастным группам снижается (Рисунок 1), отставание от развитых стран по этому параметру в относительном выражении практически не меняется.

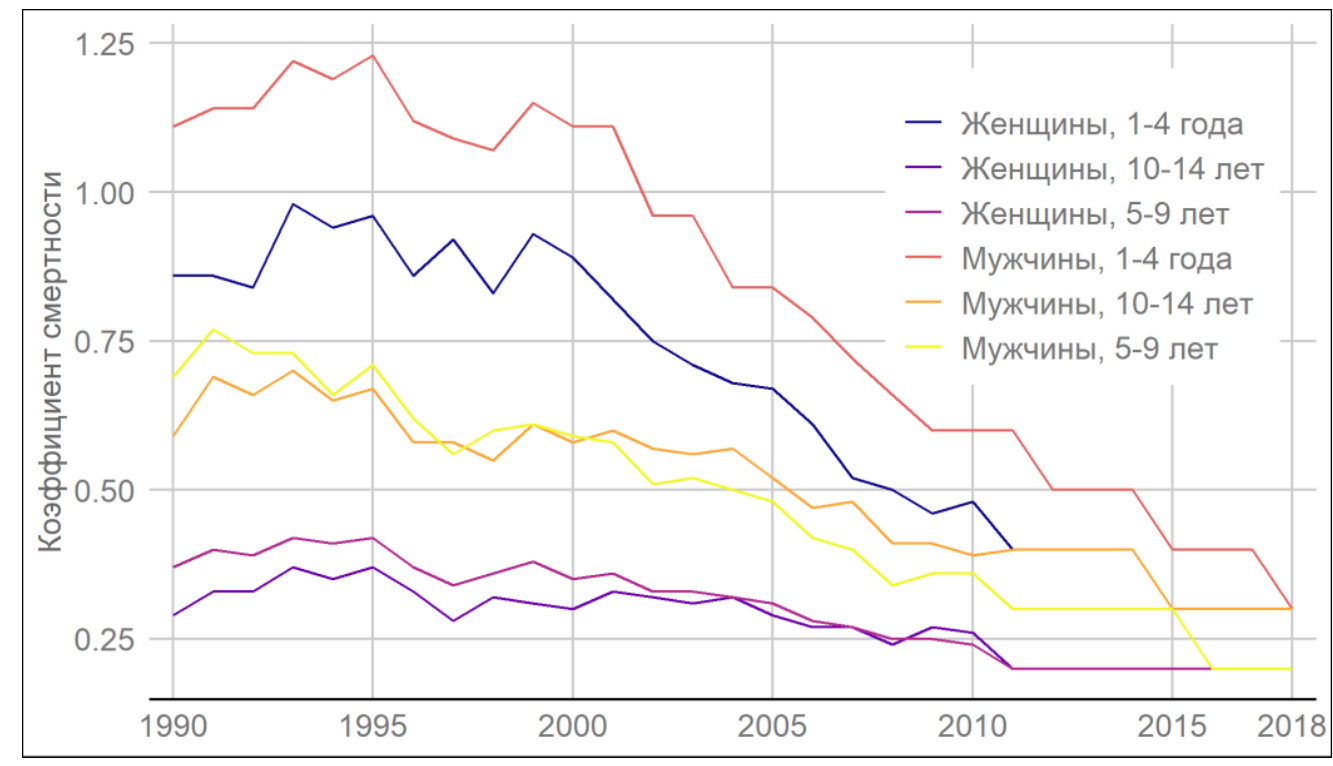

Рисунок 1. Коэффициент детской смертности по пятилетним возрастным группам и полу, Россия, 1990-2018, промилле

Источник: (Росстат 2020а).

В соответствии с совместным докладом организаций системы ООН 2019 года коэффициент смертности в возрасте до 5 лет в странах-лидерах Финляндии, Исландии и Словении составляет 2 случая на 1000 детей как для девочек, так и для мальчиков (UNICEF et al. 2019). В России аналогичный коэффициент установился на уровне 8 для мальчиков и 6 для девочек. В возрастной группе от 5 до 14 лет этот коэффициент у стран-лидеров для обоих полов установился на уровне 1, а для России он составляет 2.

От особенностей самосохранительного поведения молодежи зависит будущее экономическое развитие страны (Mokdad A.H. et al. 2016). Выявление структуры смертности по причинам в России и социальная политика, нацеленная на снижение смертности от предотвратимых причин, могут привести к снижению смертности и во взрослых возрастах. Вклад, который вносят детские возраста в отставание других регионов от Москвы по продолжительности жизни, образуется преимущественно из-за различной структуры по причинам смерти (Данилова 2017). Различия в количестве смертей по классу «Внешние причины» подтверждают необходимость исследования вклада внешних причин в межрегиональные различия детской смертности и выявления факторов, влияющих на эти различия. Снижение смертности от внешних причин позволит России приблизиться по уровню ожидаемой продолжительности жизни к странам-лидерам (Кваша, Харькова, Юмагузин 2014). 
Выявление доминирующих причин даст возможность сформулировать рекомендации относительно мер социальной политики, которая поможет снизить уровень детской и подростковой смертности в России. В европейских странах, в которых подобные исследования уже проводились, уровень детской смертности значительно снизился в результате адаптированной под преобладающие причины смертности политики, направленной на безопасность этой возрастной группы (Ekman, Svanström, Långberg 2005; Gijzen et al. 2014). Так, в Финляндии уровень детской смертности от внешних причин стабильно снижался за счет уменьшения смертельных случаев в ДТП с 57 случаев в год для девочек и 92 для мальчиков в 1971 г. до 5 для девочек и 2 для мальчиков в 2010 г. (Parkkari et al. 2013). Это стало возможным благодаря многоплановой программе по повышению безопасности на дорогах, проводимой правительством, повышению требований безопасности к автомобилям, игровым площадкам и сложности упаковки опасных для детей веществ. В Швеции аналогичная национальная стратегия по повышению безопасности включает улучшение транспортной инфраструктуры, повышение требований к использованию велосипедных шлемов, планирование безопасности в жилых районах, использование спасательных жилетов (Ekman, Svanström, Långberg 2005).

Структура причин детской смертности значительно различается в зависимости от уровня развития страны или региона. Так, высокая смертность от внешних причин в детских возрастах особенно характерна для развивающихся стран. Рекомендации по социальной политике в отношении детей для Англии и США акцентируют свое внимание на популяризации здоровых привычек среди детей и подростков, работу с общественным мнением (Hug, Sharrow, You 2017; Kasmauski 2018). Кроме того, в развитых странах, таких как США, в последнее десятилетие выявлен рост смертности подростков от суицида, который специалисты все чаще связывают с интенсивной включенностью подростков в социальные медиа (George 2019).

Влияние уровня доходов и неравенства на здоровье детей и подростков подтверждает исследование английской молодежи 2017 г. по данным Association for Young People's Health (Shah et al. 2018). Детская смертность отмечена автором как показатель, существенно реагирующий на экономические факторы. Этот эффект усиливается в результате того, что многодетные семьи, как правило, являются малообеспеченными. В результате возникает большая группа подростков, которые живут в семьях с дефицитом доходов и остро ощущают экономическое неравенство. Также гипотеза о влиянии неравенства доходов на смертность уже выдвигалась для российских регионов (Андреев, Школьников 2018).

Выявлена связь между повышенной детской смертностью и уровнем экономического развития страны в целом. В 2017 г. 98\% смертей в возрастной группе 5-15 лет приходилось на страны со средним и низким уровнем дохода, в число которых входит Россия. Можно предположить, что уровень смертности среди детей и подростков в возрасте 5-15 лет существенно зависит от уровня дохода (Masquelier 2018). Эта гипотеза подтверждается и данными о детской смертности в Англии и Уэльсе в период с 1981 по 1991 г. (Roberts, Power 1996). Снижению количества предотвратимых смертей от внешних причин: ДТП, убийств и самоубийств уделяется большое внимание как в более, так и менее 
богатых странах как важному способу достижения глобальных целей развития (Fadel et al. 2019).

На основании карты детской смертности в странах с низким и средним уровнем дохода за 2000-2017 гг. можно сделать вывод о сохраняющемся высоком неравенстве в детской смертности между странами. В 2017 г. максимальный коэффициент смертности по странам мира в возрастной группе от 1 до 5 лет превосходил минимальный в 24 раза (Burstein et al. 2019). Такие различия дают большое поле для исследования причин высокой смертности в менее развитых регионах.

На индивидуальном уровне наблюдается тенденция роста различий в детской смертности от травм между разными социальными классами. С развитием медицины смертность от травм в более обеспеченном классе существенно сократилась, в то время как для менее обеспеченных слоев населения наблюдается гораздо более медленный прогресс в снижении детской смертности по этому классу причин (Roberts, Power 1996).

Влияние экономических факторов на детскую смертность от травм подтверждается на примере Швеции, в том числе было обнаружено, что структура детской смертности различается на уровне муниципалитетов по данным за 1987-2001 гг. (Ekman, Svanström, Långberg 2005). Это подтверждает обоснованность изучения проблемы детской смертности в России не только на уровне страны, но и на уровне муниципальных образований.

В данной статье рассматривается детская и подростковая смертность в возрастах 1-18 лет в Москве как в самом населенном регионе России, в котором наблюдается значительная дифференциация социально-экономических характеристик жителей. На практике нередко социальная политика, впервые вводимая в Москве, позже распространяется на другие регионы. Например, так произошло со стимулирующими мерами по повышению рождаемости: подарки при рождении ребенка сначала ввели в роддомах Москвы, а после этого также в Московской области и других регионах. ${ }^{3}$ Таким образом, на примере Москвы можно разработать рекомендации по снижению детской и подростковой смертности с надеждой, что позже они будут распространены на другие регионы.

Для того чтобы социальная политика по снижению детской смертности была эффективна, необходимо учитывать преобладающие классы причин в детской смертности. По данным ЗАГС Москвы за 2017 г. в столице наибольшее количество смертей (155 из 537) классифицировано по Международной классификации болезней 10-го пересмотра (МКБ-10) как внешние причины заболеваемости и смертности. Далее по количеству смертей следуют классы:

- II Новообразования (112 случаев за 2017 г.);

- XVIII Симптомы, признаки и отклонения от нормы, выявленные при клинических и лабораторных исследованиях, не классифицированные в других рубриках (66 случаев);

\footnotetext{
3 Литвинова М. (2021). Первый подарок: регионы развивают практику наборов для новорожденных. URL: https://iz.ru/1205880/marta-litvinova/pervyi-podarok-regiony-razvivaiut-praktiku-naborov-dlia-novorozhdennykh 
- XVII Врожденные аномалии (пороки развития), деформации и хромосомные нарушения (48 случаев);

- VI Болезни нервной системы (43 случая).

В исследовании будет рассмотрена детская и подростковая смертность от внешних причин по возрастным группам 1-4, 5-9, 10-18 лет. В Москве смертность от внешних причин является третьим по значимости классом по всем возрастам, а в детских и подростковых возрастах этот класс доминирующий (Андреев, Кваша, Харькова 2016). Кроме того, смертность от внешних причин является предотвратимой, снизить её возможно при корректировке социальной политики (Parkkari et al. 2013; Ekman, Svanström, Långberg 2005).

\section{ӘМПИРИЧЕСКАЯ ОЦЕНКА ВЛИЯНИЯ СОЦИАЛЬНО-ЭКОНОМИЧЕСКИХ ФАКТОРОВ НА ДЕТСКУЮ И ПОДРОСТКОВУЮ СМЕРТНОСТЬ ОТ ВНЕШНИХ ПРИЧИН НА УРОВНЕ МОСКВЫ}

\section{Данные и методы}

Для проверки гипотезы о влиянии социально-экономических факторов на детскую и подростковую смертность от внешних причин были построены модели, оценивающие коэффициенты смертности от внешних причин на уровне районов Москвы. В статье рассмотрены разные спецификации моделей для возрастных групп 1-4, 5-9, 10-18 лет. Разделение детской смертности на 3 возрастные группы обосновано изменением доминирующих причин в зависимости от возраста. Например, с возрастом существенно растет вероятность смертности от непреднамеренных повреждений, убийств и самоубийств (UNICEF 2016). Кроме того, большинство предыдущих исследований фокусируются на более маленьких возрастных группах: авторы рассматривают отдельно группы до 5 лет (Amouzou et al. 2014; Burstein et al. 2019; Shen, Williamson 1997), от 5 до 10 или 15 лет (Masquelier et al. 2018; Fadel et al. 2019), от 10 или 15 до 18 лет (Viner et al. 2012).

Различия в структуре причин смерти по возрастным группам подтверждается и на данных этого исследования. На Рисунок 2 представлено распределение смертей по причинам в описанных выше возрастных группах в Москве в 2017 г. 


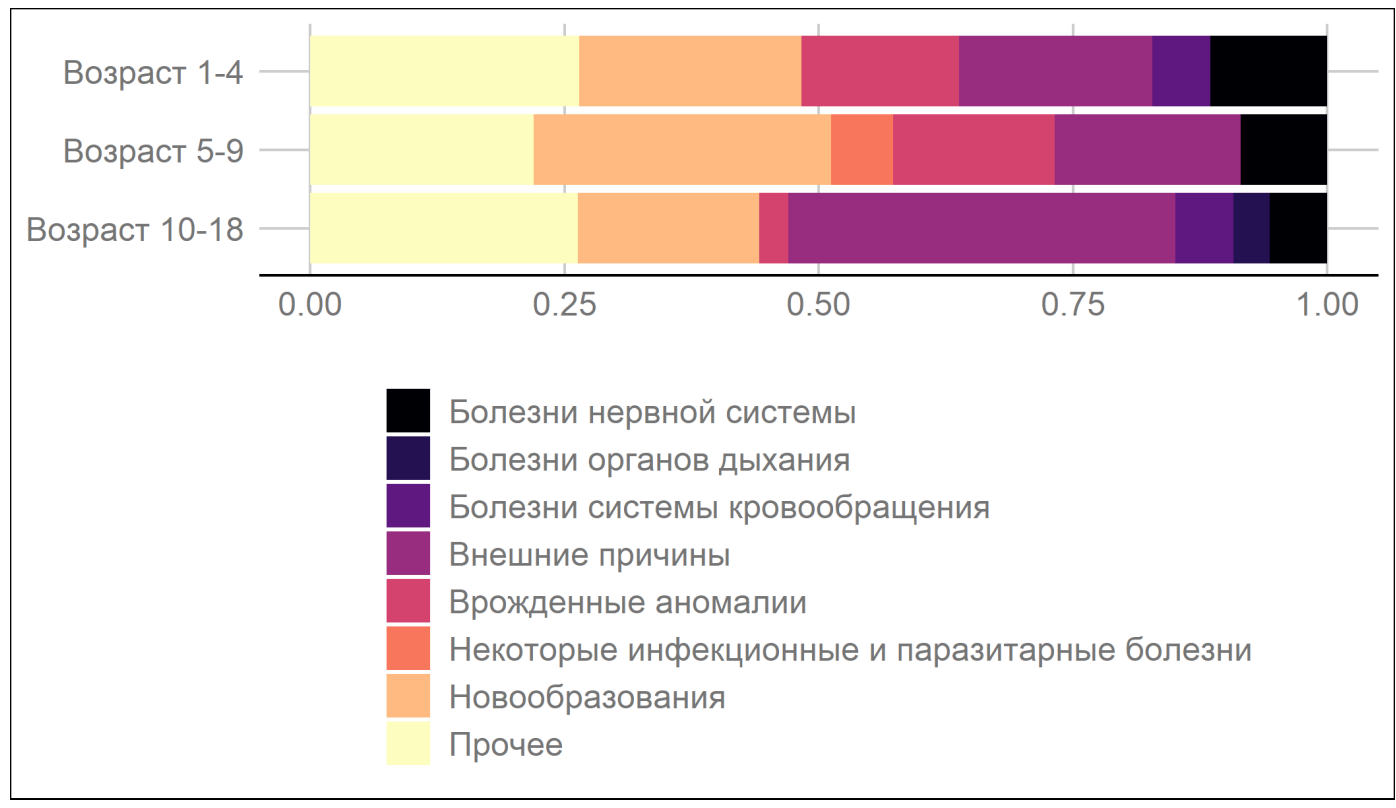

Рисунок 2. Распределение смертей в детских возрастных группах 1-4, 5-9 и 10-18 лет по группам причин смерти, Москва, 2017, доли

Источник: Построено автором на основе обезличенных данных ЗАГС Москвы.

Детскую и подростковую смертность от внешних причин по районам оценивали на основе обезличенных данных ЗАГС Москвы за 2016-2017 гг. Учтены все случаи смертей в возрасте от 1 до 18 лет на территории Москвы за этот период. Количество обработанных для исследования сертификатов о смертях сходится с оценкой смертности в Москве по данным Росстата. Количество случаев смерти от внешних причин по годам для каждой возрастной группы приведено в Таблица 1. Для каждого района за 2016-2017 гг. рассчитаны коэффициенты смертности от внешних причин в возрастных группах 1-4, 5-9, 10-18 лет. В расчетах коэффициентов использованы оценки численности населения соответствующих половозрастных групп по районам Москвы, выполненные Управлением Федеральной службы государственной статистики по г. Москве и Московской области (Управление Федеральной службы... 2020). Для определения района, в котором жил ребенок, использовали строчку из сертификата о смерти «Место постоянного жительства (регистрации) умершего(ей)».

Таблица 1. Число смертей от внешних причин в Москве по детским возрастным группам, 2016 и 2017, чел.

\begin{tabular}{l|c|c|c}
\hline \multirow{2}{*}{ Год } & \multicolumn{3}{|c}{ Возрастная группа, лет } \\
\cline { 2 - 4 } & $1-4$ & $5-9$ & 91 \\
\hline 2016 & 11 & 17 & 74 \\
2017 & 21 & 13 & 74 \\
\hline
\end{tabular}

Источник: Рассчитано автором на основе обезличенных данных ЗАГС за 2016 и 2017 г.

В качестве объясняющих переменных в блоке экономических факторов для 2016 и 2017 г. рассчитаны средняя за год стоимость квадратного метра из базы ЦИАН для каждого района Москвы, а также среднемесячная заработная плата работников организаций муниципальной формы собственности из Базы данных показателей муниципальных 
образований ${ }^{4}$ ЦЦИАН был выбран в качестве наиболее репрезентативного среза цен на жилье в Москве, так как на данный момент эта компания является одним из лидеров в предоставлении онлайн услуг по выбору жилья и занимает порядка 20,6\% рынка 5 . Оценить среднюю заработную плату всех жителей района для Москвы невозможно, так как в силу развитой инфраструктуры большая часть жителей работает за пределами того района, в котором проживает. Оценка с помощью заработной платы работников организаций муниципальной формы собственности дает представление о доходах учителей, воспитателей детских садов, сотрудников медицинских учреждений. Этот показатель может служить фактором качества оказания услуг в сфере медицины и присмотра за детьми в районе. Дополнительно включена среднемесячная номинальная начисленная заработная плата работников крупных и средних предприятий и некоммерческих организаций по муниципальным образованиям города Москвы по данным Мосстата. Включение этой переменной обосновано тем, что если в районе базируются предприятия с высоким средним уровнем заработной планы, это положительно влияет на безопасность и благосостояние этого района. Подробное описание факторов с указанием источников содержится в таблица П1 Приложения. В таблице П2 Приложения приведена описательная статистика по всем переменным, содержащимся в моделях детской смертности от внешних причин на уровне Москвы.

Москва делится на различающиеся по уровню жизни районы. Средняя стоимость квадратного метра в самом дорогом на 2017 г. районе (Арбат) составляла 508865 руб. и в 5 раз превышала стоимость квадратного метра в самом дешевом районе (Люберецкий) - 116226 руб. Значительные различия в средней стоимости жилья свидетельствуют как о достатке домохозяйств, так и об уровне неравенства в районе. По стоимости квартир на ЦИАН в 2016-2017 гг. в рамках этого исследования рассчитано, что коэффициент корреляции индекса Джини со средней ценой квадратного метра жилья внутри района составляет 0,94. Таким образом, если в районе есть дорогостоящие жилые комплексы, то это влияет как на среднюю цену, так и на неравенство внутри района.

В блоке социальных факторов для оценки присмотра за детьми использованы число мест в организациях, осуществляющих образовательную деятельность по образовательным программам дошкольного образования, присмотр и уход за детьми, число общеобразовательных организаций на начало учебного года, число детско-юношеских спортивных школ (включая филиалы) в расчете на одного ребенка в 2016-2017 гг. (Росстат $2020 b)$. Социальное благополучие районов оценивали на основе численности работников муниципальных органов охраны общественного порядка и участников добровольных формирований населения по охране общественного порядка на одного жителя района (Росстат 2020b). Также в исследовании для оценки уровня преступности использовали среднее число преступлений, совершенных на территории административного округа в

\footnotetext{
${ }^{4}$ ЦИАН. База недвижимости в Москве и Московской области. URL: https://www.cian.ru/. (Данные загружены 18.01.2020)

5 РБК (2021). Оценка объема рынка онлайн-классифайдов недвижимости в сегменте квартир и прогноз на 2021 год. URL: https://news.ners.ru/ocenka-obema-rynka-onlajn-klassifajdov-nedvizhimosti-v-segmente-kvartir-iprognoz-na-2021-god.html?utm_source=more_list
} 
расчете на жителя по статистике прокуратуры Москвы (Прокуратура города Москвы 2020). Для оценки благополучия районов включены переменные рейтинга жилой инфраструктуры на основе Яндекс.Карт и доходов местного бюджета по данным из открытого бюджета Москвы и Росстата ${ }^{6}$. Также в качестве показателей социальной обстановки в районе использован процент арендодателей-ксенофобов (процент объявлений о сдающихся квартирах, в описании которых присутствует слово «славянин») на основе объявлений с площадки «Авито» и площадь жилых помещений в расчете на человека ${ }^{7}$.

В качестве основной модели для оценки коэффициента смертности от внешних причин в детских возрастах использована Tobit-модель на основе панельных данных о смертности и социально-экономических факторах в 2016 и 2017 г. В данном случае наблюдения усеченные, коэффициент не может принимать отрицательные значения. Таким образом, оценка методом наименьших квадратов становится неприменима, предпосылки модели нарушаются (Картаев 2019). Тоbit-модель позволяет учитывать это ограничение, регрессия принимает вид:

$$
\widehat{y_{\iota}}=\left\{\begin{array}{c}
0, \text { если } y_{i}^{*}<0 \\
y_{i}^{*}, \text { если } 0<y_{i}^{*}<1, \\
1, \text { если } y_{i}^{*}>1
\end{array}\right.
$$

где $y_{i}^{*}=\sum_{j=1}^{k} x_{i j} \beta_{j}+\varepsilon_{i}, x_{i j}$ - объясняющие переменные, $y_{i}^{*}-$ прогнозное значение зависимой переменной, оцененное методом максимального правдоподобие, $\widehat{y}_{l}-$ итоговое прогнозное значение зависимой переменной.

Таким образом, прогнозные значения коэффициента смертности не могут выбиваться из интервала от 0 до 1. Модель оценивали методом максимального правдоподобия, поэтому далее в статье выбор спецификации и набора объясняющих переменных основан на показателе логарифма функции правдоподобия (Магнус, Катышев, Пересецкий 2007).

\section{Результаты оценки модели на уровне Москвы для возрастной группы 1-4 года}

Среди рассматриваемых возрастных групп самый низкий коэффициент смертности от внешних причин в группе 1-4 года. При этом он характеризуется неравномерным географическим распределением: на карте видно несколько районов, резко выделяющихся на фоне низкого среднего уровня по Москве (рисунок 3 ).

\footnotetext{
${ }^{6}$ Яндекс. Москва для жизни и развлечений. URL: https://yandex.ru/company/researches/2017/moscow_districts (данные загружены 20.04.2020).

${ }^{7}$ Авито. Недвижимость, транспорт, работа, услуги, вещи. URL: https://www.avito.ru/ (данные загружены 30.05.2021).
} 


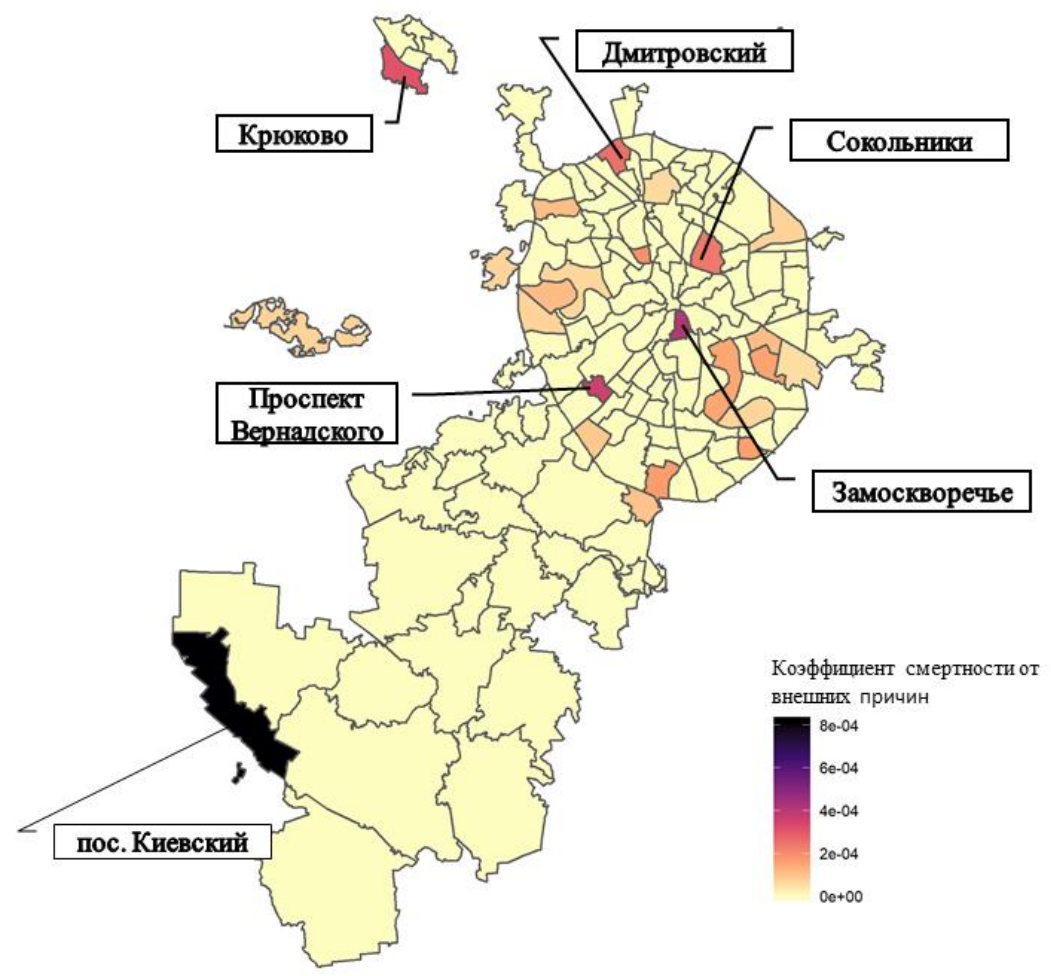

\section{Рисунок 3. Коэффициент смертности от внешних причин в возрастной группе 1-4 года, средний показатель, 2016-2017}

Источник: Построено автором на основе обезличенных индивидуальных данных ЗАГС.

На Рисунок 3 самым темным цветом выделено поселение Киевский, присоединенное к Москве, с коэффициентом смертности от внешних причин 0,0008. Следующими в рейтинге, но с показателем смертности в 2 раза ниже, идут Замоскворечье, проспект Вернадского и Крюково. Следовательно, повышенная детская смертность от внешних причин наблюдается не только в относительно более дешевых районах на периферии, но и в центральных. Это говорит о том, что процесс нельзя полностью объяснить экономическими факторами. В силу редкости наступления события существуют и случайные факторы риска.

Тест на мультиколлинеарность переменных моделей показывает её отсутствие. Направление влияния значимых переменных устойчиво к разным спецификациям.

По результатам оценки модели (таблица 2) значимым фактором является обеспеченность детей местами в детских садах. Чем больше возможностей для детей до 5 лет быть под присмотром, тем ниже коэффициент смертности от внешних причин. Численность работников муниципальных органов охраны общественного порядка на 1 жителя района также оказывает значимое влияние на показатель детской смертности от внешних причин, что говорит о важности безопасности в районе. В этой части исследования число работников муниципальных органов охраны общественного порядка на 1 жителя района оказалось наиболее значимым показателем безопасности. Таким образом, присмотр и безопасность являются наиболее приоритетными показателями для снижения смертности от внешних причин в младшей возрастной группе. 
Таблица 2. Tobit-модель оценки коэффициента смертности в возрастной группе 1-4 года по районам Москвы, 2016-2017

\begin{tabular}{lrr}
\hline & Модель 1 & \multicolumn{1}{|c}{ Модель 2} \\
\hline const & $0,21 * *$ & $0,23 * *$ \\
& $(0,106)$ & $(0,105)$ \\
Год & $-1,04 \mathrm{E}-04 * *$ & $1,15 \mathrm{E}-04$ ** \\
& $(5,29 \mathrm{E}-05)$ & $(5,21 \mathrm{E}-05)$ \\
ЦАО & $-1,04 \mathrm{E}-04$ & $-6,72 \mathrm{E}-05$ \\
Показатели дохода населения & $(1,47 \mathrm{E}-04)$ & $(1,53 \mathrm{E}-04)$ \\
Среднемесячная заработная плата работников крупных и средних & $2,34 \mathrm{E}-09$ & $2,13 \mathrm{E}-09$ \\
предприятий и некоммерческих организаций & $(1,72 \mathrm{E}-09)$ & $(1,76 \mathrm{E}-09)$ \\
Уровень неравенства & & \\
Средняя стоимость квадратного метра & $2,34 \mathrm{E}-10$ & \\
Финансовые возможности региона & $(5,47 \mathrm{E}-10)$ & \\
Доходы местного бюджета & $-5,95 \mathrm{E}-10 *$ & $-5,67 \mathrm{E}-10$ \\
Присмотр за детьми & $(3,55 \mathrm{E}-10)$ & $(3,67 \mathrm{E}-10)$ \\
Количество мест в организациях, осуществляющих & & \\
образовательную деятельность по образовательным программам & $-0,001 *$ & $-0,001 *$ \\
дошкольного образования, присмотр и уход за детьми на 1 ребенка & $(0,001)$ & $(0,001)$ \\
Показатели уровня безопасности & & \\
Число работников муниципальных органов охраны общественного & $-0,01 *$ & $-0,01 * *$ \\
порядка на 1 жителя района & $(0,006)$ & $(0,006)$ \\
Число участников добровольных формирований населения по & $-0,002$ & $-0,002$ \\
охране общественного порядка на 1 жителя района & $(0,002)$ & $(0,003)$ \\
Благополучие района & & \\
Рейтинг жилой инфраструктуры & $1,49 \mathrm{E}-06$ & $1,79 \mathrm{E}-06 *$ \\
Процент арендотателей-ксенофобов & $(1,11 \mathrm{E}-06)$ & $(9,88 \mathrm{E}-07)$ \\
& $-3,88 \mathrm{E}-06$ & $-1,99 \mathrm{E}-06$ \\
Площадь жилых помещений на 1 жителя & $(3,43 \mathrm{E}-06)$ & $(3,31 \mathrm{E}-06)$ \\
Лог. правдоподобие & $-6,97 \mathrm{E}-06$ & \\
\hline
\end{tabular}

Примечание: В скобках указаны стандартные ошибки.

*-значимость на 10\%-ном уровне; **_значимость на 5\%-ном уровне.

\section{Результаты оценки модели на уровне Москвы для возрастной группы 5-9 лет}

Коэффициенты смертности от внешних причин в возрасте 5-9 лет выше, чем в младших возрастах, однако распределены более равномерно. В этой возрастной группе разрыв между районами с самыми высокими показателями менее значительный. 


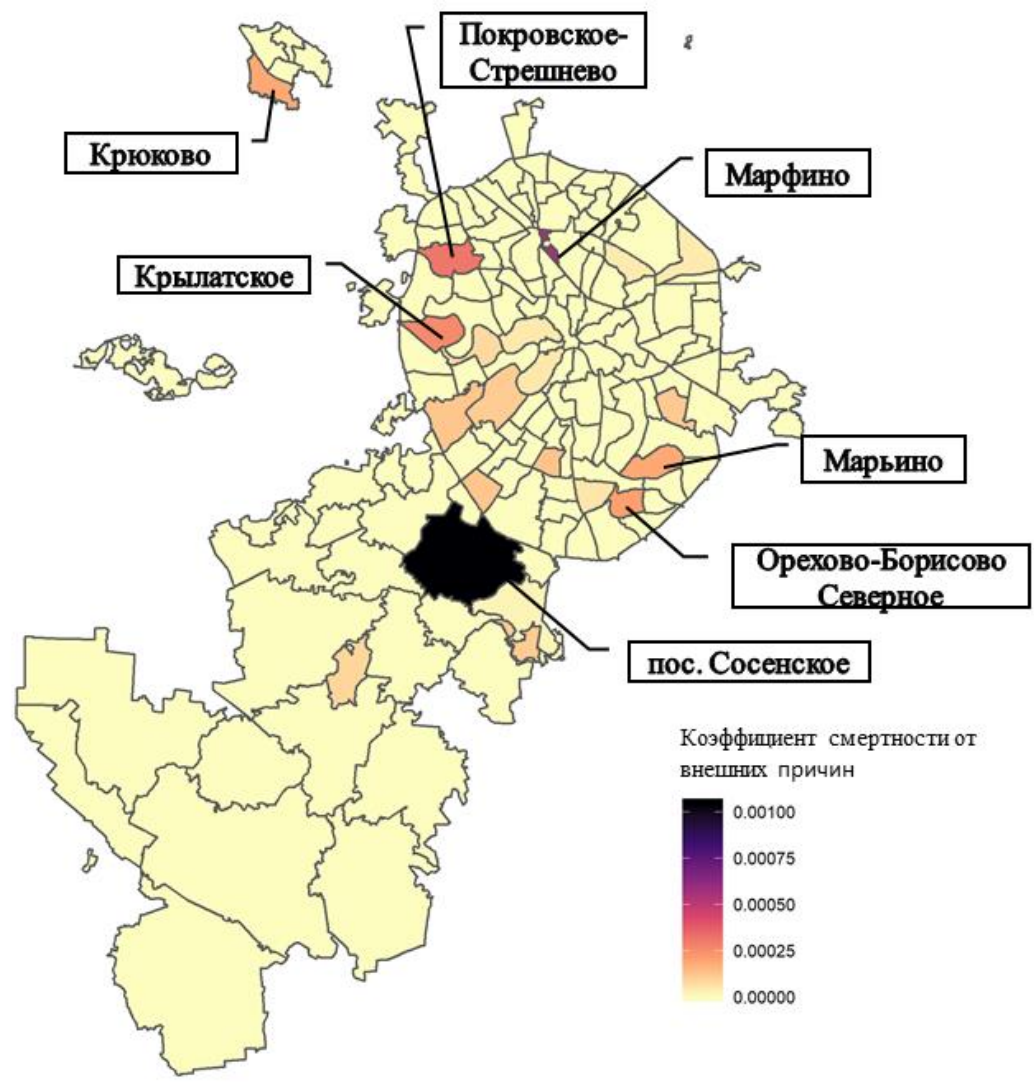

Рисунок 4. Коэффициент смертности от внешних причин в возрастной группе 5-9 лет, средний показатель, 2016-2017

Источник: Построено автором на основе обезличенных индивидуальных данных ЗАГС.

Коэффициент смертности от внешних причин составляет 0,0006 в поселении Сосенское, 0,0005 в Крылатском, 0,003 в Крюково. Также в топ-5 входят Марфино и Щербинка (Рисунок 4). В основном среди лидеров по показателю смертности от внешних причин в возрастах 5-9 лет оказались периферийные районы Москвы.

Результаты эмпирической оценки влияния социально-экономических факторов на уровень смерти от внешних причин в возрастной группе 5-9 лет приведены в таблице 3. Для возрастной группы 5-9 лет устойчиво значимое влияние оказывает численность работников муниципальных органов охраны общественного порядка. Таким образом, безопасность в районе по-прежнему снижает смертность от внешних причин.

По сравнению с младшей возрастной группой в этой модели более значимыми становятся экономические факторы. Чем выше среднемесячная заработная плата работников крупных и средних предприятий и некоммерческих организаций в районе, тем ниже смертность от внешних причин. Так как в Москве инфраструктура позволяет легко перемещаться между районами, переменная средней заработной платы местных организаций не отражает уровень доходов жителей района. Однако более успешные фирмы с высокой заработной платой с большой вероятностью будут базироваться в более благополучных районах. Кроме того, если в районе базируются успешные фирмы, это улучшает контингент жителей района. 
Таблица 3. Tobit-модель оценки коэффициента смертности в возрастной группе 5-9 лет по районам Москвы, 2016-2017

\begin{tabular}{|c|c|c|}
\hline & Модель 3 & Модель 4 \\
\hline const & $\begin{array}{r}3,01 \mathrm{E}-04 * * * \\
(1,13 \mathrm{E}-04)\end{array}$ & $\begin{array}{r}3,01 \mathrm{E}-04 * * * \\
(1,13 \mathrm{E}-04)\end{array}$ \\
\hline $\begin{array}{l}\text { Показатели дохода населения } \\
\text { Среднемесячная заработная плата работников крупных } \\
\text { и средних предприятий и некоммерческих } \\
\text { организаций }\end{array}$ & $\begin{array}{r}-3,52 \mathrm{E}-09 * * * \\
(1,22 \mathrm{E}-09)\end{array}$ & $\begin{array}{r}-2,72 \mathrm{E}-09 * * * * \\
(9,84 \mathrm{E}-10)\end{array}$ \\
\hline $\begin{array}{l}\text { Среднемесячная заработная плата работников } \\
\text { организаций муниципальной формы собственности } \\
\text { Уровень неравенства }\end{array}$ & $\begin{array}{r}-6,24 \mathrm{E}-10 \\
(1,1 \mathrm{E}-09)\end{array}$ & - \\
\hline Средняя стоимость квадратного метра & $\begin{array}{r}6,38 \mathrm{E}-10 \\
(5,94 \mathrm{E}-10)\end{array}$ & $\begin{array}{r}6,98 \mathrm{E}-10 \\
(4,8 \mathrm{E}-10)\end{array}$ \\
\hline $\begin{array}{l}\text { Присмотр за детьми } \\
\text { Количество детско-юношеских спортивных школ на } 1 \\
\text { ребенка }\end{array}$ & $\begin{array}{r}-0,03 \\
(0,021)\end{array}$ & $\begin{array}{l}-0,04 * \\
(0,021)\end{array}$ \\
\hline $\begin{array}{l}\text { Показатели уровня безопасности } \\
\text { Число работников муниципальных органов охраны } \\
\text { общественного порядка на } 1 \text { жителя района }\end{array}$ & $\begin{array}{r}-0,01 * * \\
(0,005)\end{array}$ & $\begin{array}{r}-0,01 * * \\
(0,005)\end{array}$ \\
\hline $\begin{array}{l}\text { Число участников добровольных формирований } \\
\text { населения по охране общественного порядка на } 1 \\
\text { жителя района } \\
\text { Благополучие района }\end{array}$ & $\begin{array}{r}-0,002 \\
(0,003)\end{array}$ & $\begin{array}{r}-0,001 \\
(0,003)\end{array}$ \\
\hline Рейтинг жилой инфраструктуры & $\begin{array}{r}-1,54 \mathrm{E}-06 \\
(1,22 \mathrm{E}-06)\end{array}$ & $\begin{array}{c}-1,41 \mathrm{E}-06 \\
(1,14 \mathrm{E}-06)\end{array}$ \\
\hline $\begin{array}{l}\text { Финансовые возможности района } \\
\text { Доходы местного бюджета }\end{array}$ & $\begin{array}{r}-9,71 \mathrm{E}-10 * \\
(5,53 \mathrm{E}-10)\end{array}$ & $\begin{array}{r}-8,53 \mathrm{E}-10 * \\
(5,0 \mathrm{E}-10)\end{array}$ \\
\hline $\begin{array}{l}\text { Доступность медицины } \\
\text { Количество лечебно-профилактических организаций } \\
\text { на } 1 \text { человека } \\
\text { Лог. правдоподобие }\end{array}$ & $\begin{array}{r}0,01 \\
(0,023) \\
981,6 \\
\end{array}$ & 1060 \\
\hline
\end{tabular}

Примечание: В скобках указаны стандартные ошибки.

*-значимость на 10\%-ном уровне; **-значимость на 5\%-ном уровне; ***-значимость на 1\%-ном уровне.

Другим экономическим фактором, значимым для возрастной группы 5-9 лет, является доход местного бюджета. Высокие доходы местного бюджета могут отрицательно влиять на риск смерти от внешних причин, так как эти средства расходуются на финансирование органов общественного порядка, медицинских и образовательных учреждений, т. е. дают более широкие возможности для поддержания безопасности в районе и присмотра за детьми со стороны муниципальных учреждений.

\section{Результаты оценки модели на уровне Москвы для возрастной группы 10-18 лет}

Старшая возрастная группа характеризуется самыми высокими коэффициентами смертности от внешних причин (Рисунок 5). Больше всего смертей в этой возрастной группе вызвано повреждениями с неопределенными намерениями (классификация по МКБ10 Y10-Y34), далее следует группа причин «Транспортные несчастные случаи» (V01-V99 по классификации МКБ-10) и только потом все остальные внешние причины (Brämer 1988). 


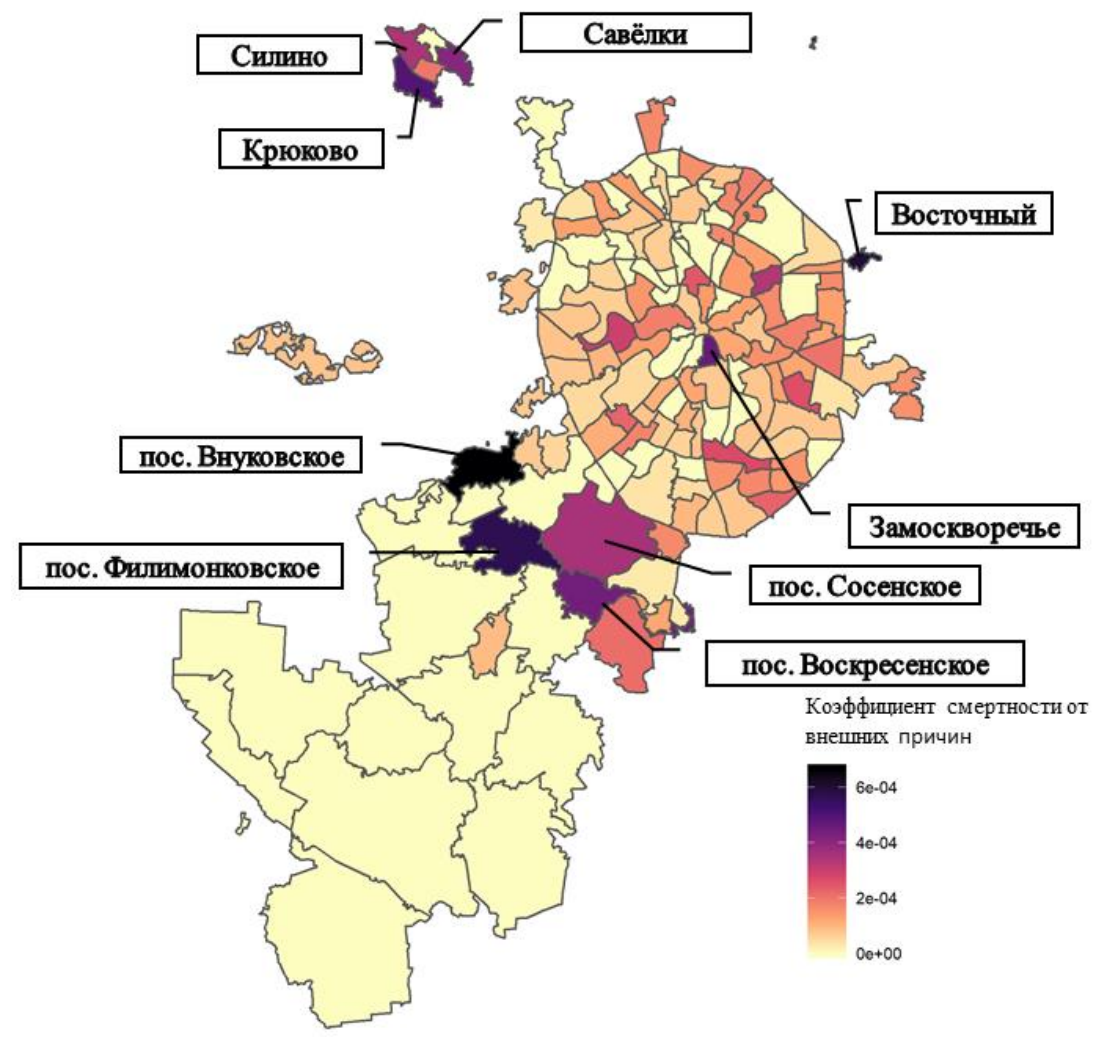

Рисунок 5. Коэффициент смертности от внешних причин в возрастной группе 10-18 лет, средний показатель, 2016-2017

Источник: Построено автором на основе обезличенных индивидуальных данных ЗАГС.

В этой возрастной группе самые высокие коэффициенты смертности от внешних причин выявлены в поселении Внуково, муниципальном округе Восточный, поселении Филимонковское, Крюково и Замоскворечье. Как и в младших возрастах, наименее благополучные по этому показателю районы расположены на периферии: присоединенные к Москве территории и районы Зеленограда.

Мультиколлинеарность в моделях отсутствует, уравнения значимы на уровне 1\% (таблица 4). Как и в модели на уровне регионов, для смертности от внешних причин в старшей возрастной группе значимую роль начинает играть преступность. Хотя в данном случае преступность оценивается только суммарном числом преступлений без выделения отдельно тяжких преступлений и убийств, для возрастов 10-18 лет этот фактор положительно влияет на смертность от внешних причин. Показателем безопасности района также является число сотрудников муниципальных органов охраны общественного порядка. Эта переменная также значима для старших возрастов. От 10 лет и старше дети всё больше передвигаются по району самостоятельно, без сопровождения родителей, поэтому уровень преступности и безопасность района становятся ещё более значимыми факторами.

Для старшей возрастной группы значимым фактором становятся условия жизни: в отличие от более младших возрастов, площадь жилых помещений в среднем на одного жителя района значима на уровне 1\%. Сохраняет своё влияние и оценка жителями инфраструктуры района. Следовательно, стесненные условия жизни, например 
многодетные семьи, проживающие в небольших по площади квартирах, провоцируют подростков проводить больше времени вне дома, что ведет к возможным травмам и смертям от внешних причин.

Таблица 4. Тоbit-модель оценки коэффициента смертности в возрастной группе 10-18 лет по районам Москвы, 2016-2017

\begin{tabular}{|c|c|c|}
\hline & Модель 5 & Модель 6 \\
\hline const & $\begin{array}{r}-0,47 \\
(0,341)\end{array}$ & $\begin{array}{r}-0,51 \\
(0,348)\end{array}$ \\
\hline Год & $\begin{array}{r}2,33 \mathrm{E}-04 \\
(1,69 \mathrm{E}-04)\end{array}$ & $\begin{array}{r}2,53 \mathrm{E}-04 \\
(1,73 \mathrm{E}-04)\end{array}$ \\
\hline ЦАО & $\begin{array}{r}-0,002 * * * \\
(0,001)\end{array}$ & $\begin{array}{r}-0,002 * * * \\
(0,001)\end{array}$ \\
\hline $\begin{array}{l}\text { Показатели дохода населения } \\
\text { Среднемесячная заработная плата работников крупных и } \\
\text { средних предприятий и некоммерческих организаций } \\
\text { Уровень неравенства }\end{array}$ & $\begin{array}{r}-7,11 \mathrm{E}-09 * \\
(3,99 \mathrm{E}-09)\end{array}$ & $\begin{array}{r}-6,92 \mathrm{E}-09 * \\
(3,97 \mathrm{E}-09)\end{array}$ \\
\hline Средняя стоимость квадратного метра & $\begin{array}{l}3,64 \mathrm{E}-09 * \\
(2,05 \mathrm{E}-09)\end{array}$ & $\begin{array}{r}5,01 \mathrm{E}-09 * * * \\
1,91 \mathrm{E}-09\end{array}$ \\
\hline Финансовые возможности района & & \\
\hline Доходы местного бюджета & $\begin{array}{r}-1,62 \mathrm{E}-09 \\
(2,77 \mathrm{E}-09)\end{array}$ & - \\
\hline Присмотр за детьми & & \\
\hline Количество детско-юношеских спортивных школ на 1 ребенка & $\begin{array}{r}0,29 \\
(0,224)\end{array}$ & $\begin{array}{r}0,32 \\
(0,232)\end{array}$ \\
\hline Показатели уровня безопасности & & \\
\hline $\begin{array}{l}\text { Количество преступлений, совершенных на территории } \\
\text { административного округа в расчете на } 1 \text { жителя } \\
\text { Число работников муниципальных органов охраны } \\
\text { общественного порядка на } 1 \text { жителя района } \\
\text { Число участников добровольных формирований населения по } \\
\text { охране общественного порядка на } 1 \text { жителя района } \\
\text { Благополучие района }\end{array}$ & $\begin{array}{r}0,06 * * \\
(0,023) \\
0,06 \\
(0,039) \\
-0,04 * * * \\
(0,010)\end{array}$ & $\begin{array}{r}0,06 * * * \\
(0,023) \\
0,06 \\
(0,037) \\
-0,03 * * * \\
(0,010)\end{array}$ \\
\hline Рейтинг жилой инфраструктуры & $\begin{array}{r}-1,09 \mathrm{E}-05 * \\
(5,76 \mathrm{E}-06)\end{array}$ & $\begin{array}{r}-9,87 \mathrm{E}-06 * \\
(5,52 \mathrm{E}-06)\end{array}$ \\
\hline Процент арендотателей-ксенофобов & $\begin{array}{l}-2,63 \mathrm{E}-05 \\
(2,01 \mathrm{E}-05)\end{array}$ & - \\
\hline Площадь жилых помещений на 1 жителя & $\begin{array}{r}-1,07 \mathrm{E}-04 * * * \\
(2,91 \mathrm{E}-05)\end{array}$ & $\begin{array}{r}-9,76 \mathrm{E}-05 * * * \\
(2,71 \mathrm{E}-05)\end{array}$ \\
\hline $\begin{array}{l}\text { Доступность медицины } \\
\text { Количество лечебно-профилактических организаций на } 1 \\
\text { человека } \\
\text { Лог. правдоподобие }\end{array}$ & $\begin{array}{r}0,17 \\
(0,106) \\
881,6\end{array}$ & $\begin{array}{r}0,16 \\
(0,107) \\
880,8\end{array}$ \\
\hline
\end{tabular}

Примечание: В скобках указаны стандартные ошибки.

*-значимость на 10\%-ном уровне; **-значимость на 5\%-ном уровне; ;**-значимость на 1\%-ном уровне.

В блоке экономических факторов значимость средней заработной платы на крупных и средних предприятиях района уменьшается, а средней стоимости квадратного метра возрастает. Положительный знак коэффициента, т. е. рост смертности от внешних причин в результате роста средней стоимости жилья, можно объяснить тем, что в данной постановке эта переменная отражает не только доход, но и неравенство внутри района. Этот вывод согласуется с результатами модели на уровне регионов. Чем выше экономическое неравенство, которое может выражаться в соседстве относительно дешевой 
застройки с элитными жилыми комплексами, тем больше это отражается на подростковой смертности от внешних причин.

Социально-экономические факторы, для которых значимое влияние на коэффициент смертности от внешних причин подтвердилось в модели на уровне Москвы, приведены для каждой возрастной группы детей в сводной Таблица 5. В моделях для средней (5-9 лет) и старшей (10-18 лет) возрастных групп значимых переменных оказалось больше, чем для младшей возрастной группы 1-4 года. Это можно объяснить тем, что для маленьких детей социальные факторы играют меньшую роль для смертности от внешних причин, чем показатели уровня медицины. Значимыми для этих возрастов могут оказаться такие показатели, как обеспеченность медицинских учреждений оборудованием и персоналом, но выявление влияния системы здравоохранения на смертность от внешних причин не было целью данного исследования.

Таблица 5. Значимые факторы детской смертности от внешних причин по итогам моделей на уровне Москвы

\begin{tabular}{c|c|c}
\hline \multicolumn{3}{c}{ Значимые факторы для каждой возрастной группы } \\
\hline $1-4$ года & $5-9$ лет & $10-18$ лет \\
\hline Финансовые возможности района & Доходы населения & Доходы населения \\
$(1 / 1)$ & $(1 / 2)$ & $(1 / 2)$ \\
Присмотр за детьми & Финансовые возможности района & Неравенство \\
$(1 / 2)$ & $(1 / 1)$ & $(1 / 1)$ \\
Безопасность & Присмотр за детьми & Безопасность \\
$(1 / 3)$ & $(1 / 2)$ & $(2 / 3)$ \\
Благополучие района & Безопасность & $(1 / 3)$ \\
$(1 / 3)$ & Благополучие района & $(2 / 3)$ \\
& $(1 / 3)$ & \\
\hline
\end{tabular}

Примечание: В скобках указано количество переменных, которые оказались значимыми в каждой группе факторов.

\section{Выводы и дискУссия}

На примере Москвы гипотеза о связи детской и подростковой смертности от внешних причин и социально-экономических особенностей территории подтверждается. Смертность от внешних причин существенно различается между районами и связана с их социальными характеристиками. Так, в возрастной группе 1-4 года самый высокий коэффициент смертности в 2016-2017 гг. наблюдался в поселении Киевский в Новой Москве, для возрастной группы 5-9 лет - это поселение Сосенское в Новой Москве, для старшей возрастной группы 10-18 лет самый высокий коэффициент был выявлен в поселении Внуково. При этом социальные детерминанты смертности значимо различаются между возрастными группами 1-4, 5-9 и 10-18 лет.

Подтверждается гипотеза о необходимости диверсифицировать социальную политику для того, чтобы сократить смертность от внешних причин в разных возрастных группах. Для младших возрастов (1-4 года) наиболее значимыми социальноэкономическими факторами оказались уровень благополучия и возможности присмотра за детьми. Следовательно, для воздействия на смертность в этих возрастах необходимо 
предоставить родителям помощь в присмотре. Для средней возрастной группы (5-9 лет), помимо присмотра и благополучия района, значимым становится уровень дохода и финансовых возможностей. В подростковых возрастах (10-15 лет) значимыми оказываются факторы доходов и уровня преступности в районе. В этих возрастах подростки становятся более самостоятельными, поэтому для снижения смертности от внешних причин необходимо повысить уровень безопасности на улице.

Таким образом, при разработке социальной политики необходимо учитывать социально-экономические факторы территории, а также дифференцировать политику для семей с детьми по возрасту ребенка.

Наше исследование имеет ряд ограничений. Для повышения точности результатов необходимо учитывать миграционные потоки и этнический состав населения района. Медианный коэффициент детской смертности в этнических группах с самой высокой смертностью может превосходить аналогичный показатель для групп с самой низкой смертностью в 3 раза в пределах одной страны (Victora et al. 2020), а для Москвы свойственны процессы миграции населения и этническое разнообразие. Однако мы недостаточно знаем о расселении этнических групп в Москве, в какой мере оно кластеризовано в определенных районах, что осложняет включение миграционных факторов в исследование.

Также среди социальных факторов смертности в возрасте до 5 лет выделяют средний уровень образования в регионе и положение женщин (Shen, Williamson 1997). Более образованные женщины могут обеспечить лучший уход для ребенка в силу финансовой обеспеченности и более высокого уровня грамотности в вопросах здоровья (Pradhan 2018). К сожалению, данных о положении женщин, их уровне здоровья, степени репродуктивной свободы, уровне образования по регионам России недостаточно.

Поскольку смерть в детском или подростковом возрасте - редкое явление по сравнению с другими возрастными группами, причины смерти имеет смысл рассматривать не только на уровне показателей для крупных социально-демографических общностей, но и на уровне личного окружения, семьи, и в локально-территориальном контексте мест проживания. Социальные детерминанты особенно значимы для смертности в возрастной группе 12-24, а для подростков имеет особенно важный смысл проверка различий в условиях жизни и характеристиках окружения в разных районах Москвы (Viner et al. 2018).

Для изучения детской и подростковой заболеваемости и смертности недостаточно количественных методов. Так как уровень здоровья детей и подростков в значительной степени объясняется поведенческими паттернами, социальным окружением и рядом других факторов, которые невозможно отследить на макроуровне, необходимо начинать исследования с качественных методов: опросов детей, подростков и их родителей (Rich, Ginsburg 1999). Изучение характеристик семей, в которых произошли случаи детской смерти от внешних причин, также могут существенно дополнить картину влияния социально-экономических факторов на смертность. 
Таким образом, дальнейшее исследование темы детской и подростковой смертности в России будет очень полезным для понимания возможных путей повышения ожидаемой продолжительности жизни и сокращения разрыва со странами-лидерами.

\section{ЛИТЕРАТУРА}

Андреев Е.М., Кваша Е.А., Харькова Т.Л. (2016). Смертность в Москве и других мегаполисах мира: сходства и различия. Демографическое обозрение, 3(3). https://doi.org/10.17323/demreview.v3i3.1746

Андреев Е.М., Школьников В.М. (2018). Связь между уровнями смертности и экономического развития в России и ее регионах. Демографическое обозрение, 5(1). https://doi.org/10.17323/demreview.v5i1.7707

Генеральная прокуратура Российской Федерации (2020). Информационно-аналитический портал правовой статистики Генеральной прокуратуры Российской Федераиии. URL: http://crimestat.ru/ (данные загружены 28.02.2019)

Данилова И.А. (2017). Межрегиональное неравенство в продолжительности жизни в России и его составляющие по возрасту и причинам смерти. Социальные аспекты здоровья населения, 57(5).

Картаев Ф.С. (2019). Введение в эконометрику: учебник. М.: Экономический факультет МГУ имени М.В. Ломоносова.

Кваша Е.А., Харькова Т.Л., Юмагузин В.В. (2014). Смертность от внешних причин в России за полвека. Демографическое обозрение, 1(4). https://doi.org/10.17323/demreview.v1i4.1803

Магнус Я.Р., Катышев П.К., Пересецкий А.А. (2007). Эконометрика. Начальный курс: учеб. 6-е изд., перераб. и доп. М.: Дело.

Прокуратура города Москвы (2020). Статистика. URL: https://old.mosproc.ru/statistics/ (данные загружены 05.05.2020)

Российская экономическая школа (2019). Российская база данных по рождаемости и смертности. Россия и регионы, по причинам смерти (краткая номенклатура 2011 г.), пятилетние возрастные группы, 2011-2014 г2. URL: http://demogr.nes.ru/index.php/ru/demogr_indicat/data (данные загружены 28.02.2019).

Росстат (2020а). Единая межведомственная информационно-статистическая система (ЕМИСС). Возрастные коэффииченты смертности. URL: https://fedstat.ru/indicator/30974 (данные загружены 28.02.2019).

Росстат (2020b). База данных показателей муниципальных образований. Москва. URL: https://www.gks.ru/dbscripts/munst/munst45/DBInet.cgi (данные загружены 05.05.2020)

Управление Федеральной службы государственной статистики по г. Москве и Московской области (2020). Численность населения до 18 лет по полу и возрасту по районам Москвы. URL: https://mosstat.gks.ru/ (данные загружены 05.03.2020)

Amouzou A., Kozuki N., Gwatkin D.R. (2014). Where is the gap?: the contribution of disparities within developing countries to global inequalities in under-five mortality. BMC public health, 14(1), 1-5.

Assembly G. (2015) Sustainable development goals //SDGs Transform Our World. - T. 2030. 
Brämer G.R. (1988). International statistical classification of diseases and related health problems. Tenth revision. World Health Statistics Quarterly. Rapport Trimestriel de Statistiques Sanitaires Mondiales. https://doi.org/978924 549165

Burstein R., Henry N.J., Collison M.L. et al. (2019). Mapping 123 million neonatal, infant and child deaths between 2000 and 2017. Nature 574, 353-358. https://doi.org/10.1038/s41586019-1545-0

Ekman R., Svanström L., Långberg B. (2005). Temporal trends, gender, and geographic distributions in child and youth injury rates in Sweden. Injury Prevention, 11(1), 29-

32.

Fadel S.A., Cynthia B.P., Shicheng Y., Reynales-Shigematsu L.M., Menon G.R., Newcombe L., Strong K.L., Wang Q., Prabhat J. (2019). Trends in cause-specific mortality among children aged 5-14 years from 2005 to 2016 in India, China, Brazil, and Mexico: an analysis of nationally representative mortality studies. The Lancet, 393(10176), 1119-1127.

George M. (2019). The importance of social media content for teens' risks for self-harm. Journal of Adolescent Health, 65(1), 9-10.

Gijzen S., Boere-Boonekamp M.M., L'hoir M.P., Need A. (2014). Child mortality in the Netherlands in the past decades: an overview of external causes and the role of public health policy. Journal of public health policy, 35(1), 43-59.

Hug L., Sharrow D., You D. (2017). Levels \& Trends in Child Mortality: Report. Estimates Developed by the UN Inter-agency Group for Child Mortality Estimation.

Kasmauski K. (2018). Type 2 diabetes: The urgent need to protect young people. Lancet, 392(2325), 33015-0.

Masquelier B. (2018). Mortality between ages 5 and 15. Population Societies, (9), 1-4.

Mokdad A.H. et al. (2016). Global burden of diseases, injuries, and risk factors for young people's health during 1990-2013: a systematic analysis for the Global Burden of Disease Study 2013. The Lancet, 387(10036), 2383-2401.

Molcho M., Walsh S., Donnelly P., Matos M.G.D., Pickett W. (2015). Trend in injury-related mortality and morbidity among adolescents across 30 countries from 2002 to 2010. The European Journal of Public Health, 25(suppl_2), 33-36.

Parkkari J., Mattila V., Kivistö J., Niemi S., Palvanen M., Kannus P. (2013). Fatal childhood injuries in Finland, 1971-2010. Injury prevention, 19(3), 171-176.

Pradhan E. (2018). The relationship between women's education and fertility. Weforum.

Rajaratnam J.K., Marcus J.K., Flaxman A.D., Wang H., Levin-Rector A., Dwyer L., Costa M., Lopez A.D., Murray C.J. (2010). Neonatal, postneonatal, childhood, and under-5 mortality for 187 countries, 1970-2010: a systematic analysis of progress towards Millennium Development Goal 4. The Lancet, 375(9730), 1988-2008. Rich M., Ginsburg K.R. (1999). The reason and rhyme of qualitative research: why, when, and how to use qualitative methods in the study of adolescent health. Journal of Adolescent health, 25(6), 371-378.

Roberts I., Power C. (1996). Does the decline in child injury mortality vary by social class? A comparison of class specific mortality in 1981 and 1991. Bmj, 313(7060), 784-786.

Shah R., Viner R., Hargreaves D., Heys M., Varnes M., Hagell A. (2018). The social determinants of young people's health. Health Foundation. https://www.health.org.uk/publications/the-social-determinants-of-youngpeople\%E2\%80\%99s-health 
Shen C., Williamson J.B. (1997). Child mortality, women's status, economic dependency, and state strength: a cross-national study of less developed countries. Social Forces, 76(2), 667700 .

UNICEF (2016). Adolescent Mortality. Patterns of mortality change as children enter adolescence.

UNICEF, WHO, World Bank Group, United Nations (2019). Levels \& Trends in Child Mortality. Report. https://www.unicef.org/media/60561/file/UN-IGME-child-mortalityreport-2019.pdf

Victora C.G., Barros A.J., Blumenberg C., Costa J.C., Vidaletti L.P., Wehrmeister F.C., Masquelier B., Hug L., You D. (2020). Association between ethnicity and under-5 mortality: analysis of data from demographic surveys from 36 low-income and middle-income countries. The Lancet Global Health, 8(3), e352-e361.

Viner R.M., Ozer E.M., Denny S., Marmot M., Resnick M., Fatusi A., Currie C. (2012). Adolescence and the social determinants of health. The Lancet, 379(9826), 1641-1652.

World Health Organization (2014). Targets and indicators for Health 2020. WHO Regional Office for Europe. 


\section{ПРИЛОЖЕНИЕ}

\section{Таблица П1. Расшифровка переменных, которые используются в модели вклада внешних причин в разницу ожидаемой продолжительности жизни при рождении на уровне Москвы}

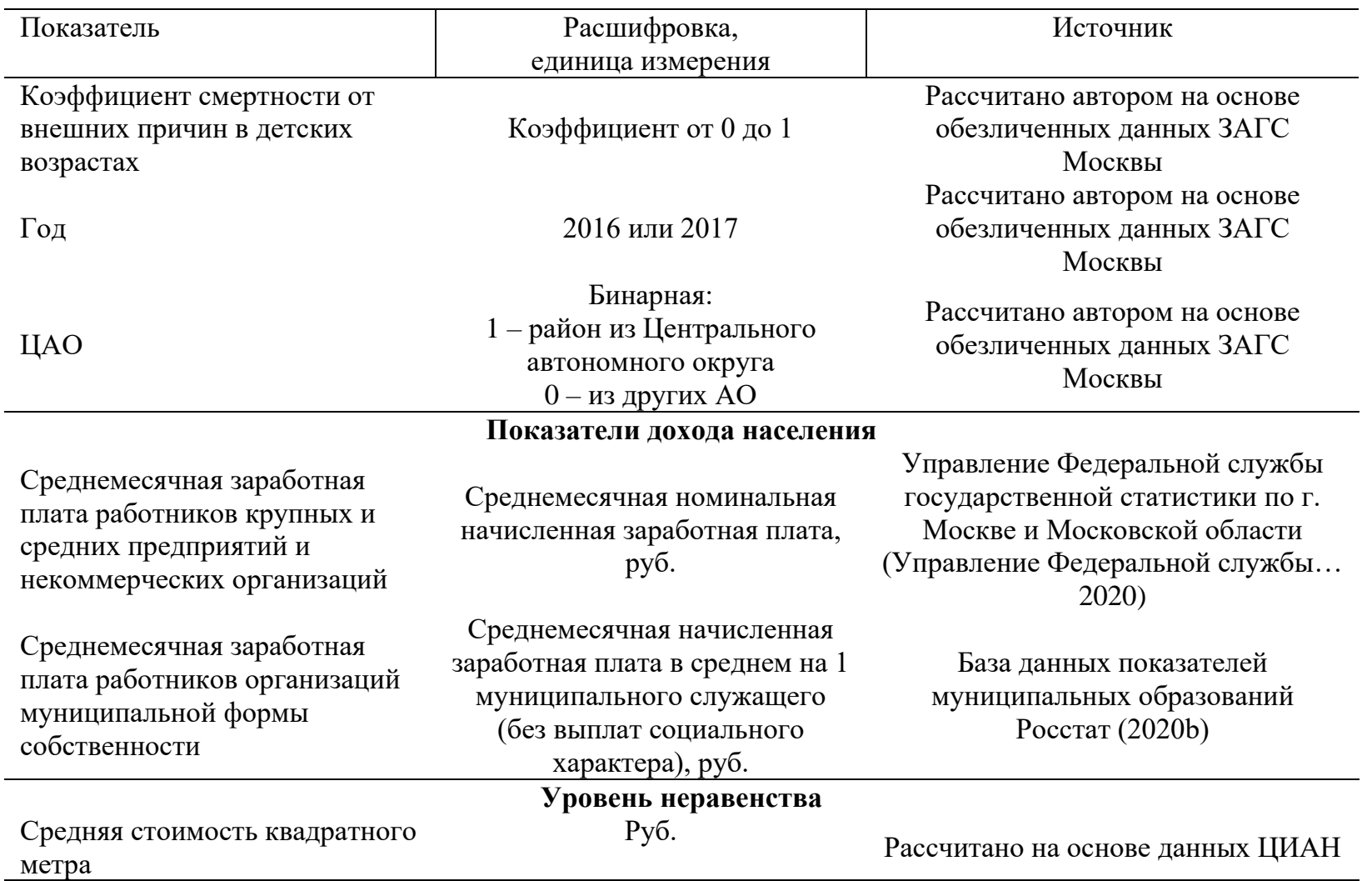
метра

Доходы местного бюджета

Финансовые возможности района Тыс. руб.

Количество мест в Присмотр за детьми

организациях, осуществляющих образовательную деятельность по образовательным программам дошкольного

Количество мест в среднем на 1 ребенка

образования, присмотр и уход

за детьми на 1 ребенка

Количество детско-юношеских спортивных школ на 1 ребенка

Количество преступлений, совершенных на территории административного округа в расчете на жителя Число работников муниципальных органов охраны общественного порядка на 1 жителя района Число участников добровольных формирований населения по охране общественного порядка на 1 жителя района
Количество школ в районе в среднем на 1 ребенка

\section{Показатели уровня преступности}

Среднее количество на 1 жителя административного округа

Среднее число на 1 жителя района

Среднее число на 1 жителя района
База данных показателей муниципальных образований Росстат (2020b)

База данных показателей муниципальных образований Росстат (2020b)

Портал правовой статистики Генеральной прокуратуры РФ (Генеральная прокуратура... 2020)

База данных показателей муниципальных образований Росстат (2020b)

База данных показателей муниципальных образований Росстат (2020b) 


\begin{tabular}{|c|c|c|}
\hline Показатель & $\begin{array}{c}\text { Расшифровка, } \\
\text { единица измерения }\end{array}$ & Источник \\
\hline \multicolumn{3}{|c|}{ Благополучие района } \\
\hline $\begin{array}{l}\text { Рейтинг жилой } \\
\text { инфраструктуры }\end{array}$ & Рейтинг в баллах от 0 до 100 & Исследование Яндекс \\
\hline $\begin{array}{l}\text { Количество арендотателей- } \\
\text { ксенофобов, \% }\end{array}$ & $\begin{array}{c}\text { Количество объявлений о } \\
\text { сдающихся квартирах, в } \\
\text { описании которых } \\
\text { присутствует слово «славян», \% }\end{array}$ & $\begin{array}{c}\text { Исследование на основе объявлений } \\
\text { на сайте Авито }\end{array}$ \\
\hline $\begin{array}{l}\text { Площадь жилых помещений на } \\
1 \text { жителя }\end{array}$ & Квадратных метров на 1 жителя & $\begin{array}{c}\text { База данных показателей } \\
\text { муниципальных образований } \\
\text { Росстат (2020b) }\end{array}$ \\
\hline \multicolumn{3}{|c|}{ Доступность медицины } \\
\hline $\begin{array}{l}\text { Количество лечебно- } \\
\text { профилактических организаций } \\
\text { на человека }\end{array}$ & $\begin{array}{c}\text { Среднее количество на } 1 \\
\text { жителя района }\end{array}$ & $\begin{array}{c}\text { База данных показателей } \\
\text { муниципальных образований } \\
\text { Росстат (2020b) }\end{array}$ \\
\hline
\end{tabular}

\section{Таблица П2. Описательная статистика данных для региональной модели оценки смертности от внешних причин}

\begin{tabular}{|c|c|c|c|c|}
\hline Показатель & Среднее & Медиана & Минимум & Максимум \\
\hline $\begin{array}{l}\text { Коэффициент смертности от внешних } \\
\text { причин в возрасте 1-4 }\end{array}$ & $5,30 \mathrm{E}-05$ & 0 & 0 & 0,003 \\
\hline $\begin{array}{l}\text { Коэффициент смертности от внешних } \\
\text { причин в возрасте 5-9 }\end{array}$ & $1,31 \mathrm{E}-04$ & 0 & 0 & 0,008 \\
\hline $\begin{array}{l}\text { Коэффициент смертности от внешних } \\
\text { причин в возрасте } 10-18\end{array}$ & $9,15 \mathrm{E}-04$ & 0 & 0 & 0,014 \\
\hline Год & 2016,5 & 2017 & 2016 & 2017 \\
\hline ЦАО & 0,1 & 0 & 0 & 1 \\
\hline \multicolumn{5}{|c|}{ Показатели дохода населения } \\
\hline $\begin{array}{l}\text { Среднемесячная заработная плата } \\
\text { работников крупных и средних } \\
\text { предприятий и некоммерческих } \\
\text { организаций, руб. }\end{array}$ & 75507 & 69875 & 23063 & 176540 \\
\hline $\begin{array}{l}\text { Среднемесячная заработная плата } \\
\text { работников организаций муниципальной } \\
\text { формы собственности, руб. }\end{array}$ & 91327 & 93667 & 11327 & 203960 \\
\hline \multicolumn{5}{|c|}{ Уровень неравенства } \\
\hline Средняя стоимость квадратного метра, руб. & 190490 & 169470 & 62037 & 508870 \\
\hline \multicolumn{5}{|c|}{ Финансовые возможности района } \\
\hline Доходы местного бюджета, руб. & 26668 & 21604 & 12722 & 242370 \\
\hline \multicolumn{5}{|c|}{ Присмотр за детьми } \\
\hline $\begin{array}{l}\text { Количество мест в организациях, } \\
\text { осуществляющих образовательную } \\
\text { деятельность по образовательным } \\
\text { программам дошкольного образования, } \\
\text { присмотр и уход за детьми на } 1 \text { ребенка }\end{array}$ & 0,26 & 0,22 & 0,02 & 1,18 \\
\hline $\begin{array}{l}\text { Количество детско-юношеских спортивных } \\
\text { школ на } 1 \text { ребенка }\end{array}$ & $2,08 \mathrm{E}-04$ & $1,25 \mathrm{E}-04$ & $3,05 \mathrm{E}-05$ & $3,93 \mathrm{E}-03$ \\
\hline \multicolumn{5}{|c|}{ Показатели уровня преступности } \\
\hline $\begin{array}{l}\text { Количество преступлений, совершенных на } \\
\text { территории административного округа в } \\
\text { расчете на } 1 \text { жителя }\end{array}$ & 0,02 & 0,02 & 0,02 & 0,04 \\
\hline $\begin{array}{l}\text { Число работников муниципальных органов } \\
\text { охраны общественного порядка на } 1 \\
\text { жителя района }\end{array}$ & 7,87E-04 & $4,50 \mathrm{E}-04$ & $1,14 \mathrm{E}-04$ & $1,50 \mathrm{E}-02$ \\
\hline $\begin{array}{l}\text { Число участников добровольных } \\
\text { формирований населения по охране } \\
\text { общественного порядка на } 1 \text { жителя района }\end{array}$ & 0,01 & 0,01 & 0,00 & 0,08 \\
\hline
\end{tabular}




\begin{tabular}{|c|c|c|c|c|}
\hline Показатель & Среднее & Медиана & Минимум & Максимум \\
\hline \multicolumn{5}{|c|}{ Благополучие района } \\
\hline Рейтинг жилой инфраструктуры & 73 & 77 & 0 & 100 \\
\hline Количество арендотателей-ксенофобов, \% & 20,7 & 21,9 & 3,4 & 35,6 \\
\hline $\begin{array}{l}\text { Площадь жилых помещений на } 1 \text { жителя, } \\
\text { м² }^{2}\end{array}$ & 24,3 & 18,6 & 10,5 & 174,1 \\
\hline \multicolumn{5}{|c|}{ Доступность медицины } \\
\hline $\begin{array}{l}\text { Количество лечебно-профилактических } \\
\text { организаций на } 1 \text { человека }\end{array}$ & $1,38 \mathrm{E}-03$ & $1,08 \mathrm{E}-03$ & $1,61 \mathrm{E}-04$ & $9,13 \mathrm{E}-03$ \\
\hline
\end{tabular}




\title{
SOCIO-ECONOMIC DETERMINANTS OF CHILD
}

\section{AND ADOLESCENT MORTALITY FROM EXTERNAL CAUSES IN MOSCOW}

\author{
EKATERINA VETROVA
}

\begin{abstract}
Child and adolescent mortality in Russia exceeds the indicators of the leading countries in terms of life expectancy. A significant contribution to this comes from mortality from external causes. The experience of other countries shows that it is possible to reduce mortality from this class of causes through social policy measures. The article analyzes the influence of social and economic characteristics of Moscow districts on mortality from external causes in them among children and adolescents in 2016-2017. Based on data from the Federal State Statistics Service, CIAN, the Database of indicators of municipalities, as well as anonymous data from the Moscow registry office, maps of the infant mortality rate of Moscow and a Tobit model for assessing the mortality rate depending on the social characteristics of the area were constructed. It was revealed that for the younger age group from 1 to 4 years, the most significant factor is parental supervision, while for the older groups, 5-9, the indicators of income and well-being of the district become significant. For adolescents aged 10-15, in addition to income, the crime rate in the region and the level of economic inequality are significant.
\end{abstract}

Key words: child mortality, social policy, regional policy, external causes of death, excess mortality.

EKATERINA VeTrova (ekat.vetrova@gmal.com), LOMONOSOv Moscow STATE University, Russia.

DATE RECEIVED : JULY 2021.

\section{REFERENCES}

Amouzou A., Kozuki N., Gwatkin D.R. (2014). Where is the gap?: the contribution of disparities within developing countries to global inequalities in under-five mortality. BMC public health, 14(1), 1-5.

Andreev E.M., Kvasha E.A., Kharkova T.L. (2016). Smertnost' v Moskve i drugikh megapolisakh mira: skhodstva i razlichiya [Mortality in Moscow and other megacities of the world: similarities and differences]. Demographic Review, 3(3). https://doi.org/10.17323/demreview.v3i3.1746 (In Russ.)

Andreev E.M., Shkolnikov V.M. (2018). Svyaz' mezhdu urovnyami smertnosti i ekonomicheskogo razvitiya $\mathrm{v}$ Rossii i yeye regionakh [The relationship between mortality and economic development in Russia and its regions]. Demographic Review, 5(1). https://doi.org/10.17323/demreview.v5i1.7707 (In Russ.)

Assembly G. (2015) Sustainable development goals //SDGs Transform Our World. - T. 2030.

Brämer G.R. (1988). International statistical classification of diseases and related health problems. Tenth revision. World Health Statistics Quarterly. Rapport Trimestriel de Statistiques Sanitaires Mondiales. https://doi.org/978924 549165

Burstein R., Henry N.J., Collison M.L. et al. (2019). Mapping 123 million neonatal, infant and child deaths between 2000 and 2017. Nature 574, 353-358. https://doi.org/10.1038/s41586019-1545-0 
Center for Demographic Research (2019). Russian Fertility and Mortality Database. URL: http://demogr.nes.ru/index.php/ru/demogr_indicat/data (data downloaded on 28.02.2019).

Danilova I.A. (2017) Mezhregional'noye neravenstvo v prodolzhitel'nosti zhizni v Rossii i yego sostavlyayushchiye po vozrastu i prichinam smerti [Interregional inequality in life expectancy in Russia and its age and cause of death components]. Social aspects of population health, 57(5). DOI: 10.21045/2071-5021-2017-57-5-3 (In Russ.).

Ekman R., Svanström L., Långberg B. (2005). Temporal trends, gender, and geographic distributions in child and youth injury rates in Sweden. Injury Prevention, 11(1), 29-32.

Fadel S.A., Cynthia B.P., Shicheng Y., Reynales-Shigematsu L.M., Menon G.R., Newcombe L., Strong K.L., Wang Q., Prabhat J. (2019). Trends in cause-specific mortality among children aged 5-14 years from 2005 to 2016 in India, China, Brazil, and Mexico: an analysis of nationally representative mortality studies. The Lancet, 393(10176), 1119-1127.

General'naya prokuratura Rossiyskoy Federatsii [General Prosecutor's Office of the Russian Federation] (2020). Informatsionno-analiticheskiy portal pravovoy statistiki General'noy prokuratury Rossiyskoy Federatsii [Information and analytical portal of legal statistics of the General Prosecutor's Office of the Russian Federation]. URL: http://crimestat.ru/ (data downloaded on 28.02.2019).

George M. (2019). The importance of social media content for teens' risks for self-harm. Journal of Adolescent Health, 65(1), 9-10.

Gijzen S., Boere-Boonekamp M.M., L'hoir M.P., Need A. (2014). Child mortality in the Netherlands in the past decades: an overview of external causes and the role of public health policy. Journal of public health policy, 35(1), 43-59.

Hug L., Sharrow D., You D. (2017). Levels \& Trends in Child Mortality: Report. Estimates Developed by the UN Inter-agency Group for Child Mortality Estimation.

Kartaev F.S. (2019). Vvedenie v ekonometriku: uchebnik [Introduction to econometrics: textbook] Moscow: Lomonosov Moscow State University, Faculty of Economics. (In Russ.).

Kasmauski K. (2018). Type 2 diabetes: The urgent need to protect young people. Lancet, 392(2325), 33015-0.

Kvasha E.A., Kharkova T.L., Yumaguzin V.V. (2014). Smertnost' ot vneshnikh prichin v Rossii za polveka [Mortality from external causes of death in Russia over the past half-century]. Demographic Review, 1(4). https://doi.org/10.17323/demreview.v1i4.1803 (In Russ.).

Magnus YA.R., Katyshev P.K., Pereseckij A.A. (2007). Ekonometrika. Nachal'nyj kurs: ucheb. 6-e izd. [Introduction to the theory of econometrics: textbook]. Moscow: Delo. (In Russ).

Masquelier B. (2018). Mortality between ages 5 and 15. Population Societies, (9), 1-4.

Mokdad A.H. et al. (2016). Global burden of diseases, injuries, and risk factors for young people's health during 1990-2013: a systematic analysis for the Global Burden of Disease Study 2013. The Lancet, 387(10036), 2383-2401.

Molcho M., Walsh S., Donnelly P., Matos M.G.D., Pickett W. (2015). Trend in injury-related mortality and morbidity among adolescents across 30 countries from 2002 to 2010. The European Journal of Public Health, 25(suppl_2), 33-36.

Parkkari J., Mattila V., Kivistö J., Niemi S., Palvanen M., Kannus P. (2013). Fatal childhood injuries in Finland, 1971-2010. Injury prevention, 19(3), 171-176.

Pradhan E. (2018). The relationship between women's education and fertility. Weforum. 
Prokuratura goroda Moskvy [The Prosecutor's Office of the city of Moscow] (2020). Statistika [Statistics]. URL: https://old.mosproc.ru/statistics/ (data downloaded on 05.05.2020).

Rajaratnam J.K., Marcus J.K., Flaxman A.D., Wang H., Levin-Rector A., Dwyer L., Costa M., Lopez A.D., Murray C.J. (2010). Neonatal, postneonatal, childhood, and under-5 mortality for 187 countries, 1970-2010: a systematic analysis of progress towards Millennium Development Goal 4. The Lancet, 375(9730), 1988-2008.

Rich M., Ginsburg K.R. (1999). The reason and rhyme of qualitative research: why, when, and how to use qualitative methods in the study of adolescent health. Journal of Adolescent health, 25(6), 371-378.

Roberts I., Power C. (1996). Does the decline in child injury mortality vary by social class? A comparison of class specific mortality in 1981 and 1991. Bmj, 313(7060), 784-786.

Rosstat [Federal State Statistics Service] (2020a). Yedinaya mezhvedomstvennaya informatsionno-statisticheskaya sistema (EMISS). Vozrastn·yye koeffitsiyenty smertnosti [Unified Interdepartmental Statistical Information System (EMISS). Age-specific mortality rates]. URL: https://fedstat.ru/indicator/30974 (data downloaded on 28.02.2019).

Rosstat [Federal State Statistics Service] (2020b). Baza dannykh pokazateley munitsipal'nykh obrazovaniy [Database of indicators of municipalities]. URL: https://www.gks.ru/dbscripts/munst/munst45/DBInet.cgi (data downloaded on 05.05.2020).

Shah R., Viner R., Hargreaves D., Heys M., Varnes M., Hagell A. (2018). The social determinants of young people's health. Health Foundation. https://www.health.org.uk/publications/the-social-determinants-of-youngpeople\%E2\%80\%99s-health

Shen C., Williamson J.B. (1997). Child mortality, women's status, economic dependency, and state strength: a cross-national study of less developed countries. Social Forces, 76(2), 667700 .

UNICEF (2016). Adolescent Mortality. Patterns of mortality change as children enter adolescence.

UNICEF, WHO, World Bank Group, United Nations (2019). Levels \& Trends in Child Mortality. Report https://www.unicef.org/media/60561/file/UN-IGME-child-mortalityreport-2019.pdf

Upravleniye Federal'noy sluzhby gosudarstvennoy statistiki po g. Moskve i Moskovskoy oblasti [Office of the Federal State Statistics Service for Moscow and the Moscow Region] (2020). Chislennost' naseleniya do 18 let po polu i vozrastu po rayonam Moskvy [Population under 18 years old by sex and age by districts of Moscow]. URL: https://mosstat.gks.ru/ (data uploaded 05.03.2020).

Victora C.G., Barros A.J., Blumenberg C., Costa J.C., Vidaletti L.P., Wehrmeister F.C., Masquelier B., Hug L., You D. (2020). Association between ethnicity and under-5 mortality: analysis of data from demographic surveys from 36 low-income and middle-income countries. The Lancet Global Health, 8(3), e352-e361.

Viner R.M., Ozer E.M., Denny S., Marmot M., Resnick M., Fatusi A., Currie C. (2012). Adolescence and the social determinants of health. The Lancet, 379(9826), 1641-1652.

World Health Organization (2014). Targets and indicators for Health 2020. WHO Regional Office for Europe. 